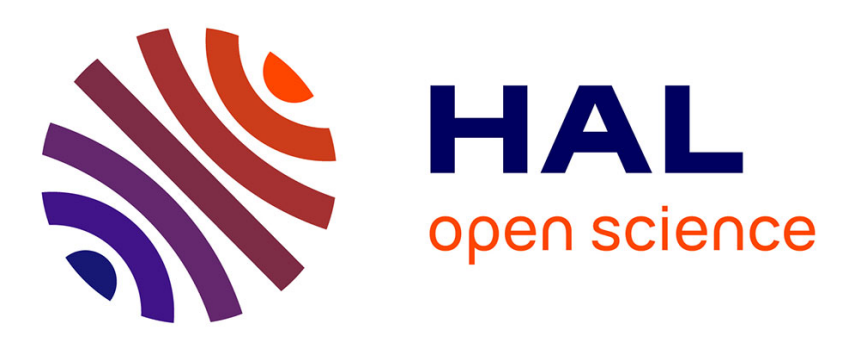

\title{
A Cognitive Perspective on Consumers' Resistances to Smart Products
}

\author{
Stefan Raff, Daniel Wentzel
}

\section{To cite this version:}

Stefan Raff, Daniel Wentzel. A Cognitive Perspective on Consumers' Resistances to Smart Products. International Working Conference on Transfer and Diffusion of IT (TDIT), Jun 2018, Portsmouth, United Kingdom. pp.30-44, 10.1007/978-3-030-04315-5_3 . hal-02071701

\section{HAL Id: hal-02071701 \\ https://hal.inria.fr/hal-02071701}

Submitted on 18 Mar 2019

HAL is a multi-disciplinary open access archive for the deposit and dissemination of scientific research documents, whether they are published or not. The documents may come from teaching and research institutions in France or abroad, or from public or private research centers.
L'archive ouverte pluridisciplinaire HAL, est destinée au dépôt et à la diffusion de documents scientifiques de niveau recherche, publiés ou non, émanant des établissements d'enseignement et de recherche français ou étrangers, des laboratoires publics ou privés.

\section{(c)(1)}

Distributed under a Creative Commons Attribution| 4.0 International License 


\title{
A Cognitive Perspective on Consumers' Resistances to Smart Products
}

\author{
Stefan Raff ${ }^{1}$ and Daniel Wentzel ${ }^{2}$ \\ ${ }^{1}$ Department of Marketing, TIME Research Area, RWTH Aachen University, 52072 Aachen, \\ Germany \\ raffetime.rwth-aachen.de \\ ${ }^{2}$ Department of Marketing, TIME Research Area, RWTH Aachen University, 52072 Aachen, \\ Germany \\ wentzel@time.rwth-aachen.de
}

\begin{abstract}
Despite their increasing relevance, research falls short to reveal the key factors hindering the adoption of smart technologies. Therefore, the aim of this exploratory study was to elicit consumers' cognitive representations, i.e. mental models of different smart product concepts based on similarity and dissimilarity judgments, and to label the key dimensions based on which consumers mentally categorize them. This was expected to shed light on drivers of adoption resistance in order to help practitioners in product design and promotion. An innovative mix of two research methods was applied, namely quantitative-descriptive projective mapping and free associations. We found that consumers mentally balance released smart product concepts along with a rationally laden 'useful-useless' dimension and unreleased concepts along with an emotionally laden 'intrusive-useful' dimension. Additionally, this research showcases (1) method diversity in the field of IS and (2) how non-IS scholars who apply new approaches to an IS phenomenon contribute with new perspectives and thus enrich the field as a whole. This is work in progress and part of an overarching mixed-method agenda. The exploratory findings will be used to carve out further research directions for this growing field (e.g. the development of a construct measuring consumers' perceived intrusion of smart products).
\end{abstract}

Keywords: Smart product - Internet of Things - ICT - Innovation resistance · Adoption barrier $\cdot$ Mental model $\cdot$ Mixed-method research

\section{Introduction}

In the past decade, the term "smart product" has been buzzing around among politicians, scientists and technology experts [e.g., 66, 68]. For a long time, this terminology appeared to be used mainly for the purpose of philosophizing in technology think tanks and for the marketing of cutting-edge information and communication technology (ICT) at trade fairs. However, driven by advancements in technology, smart products are becoming a tangible reality in the dawn of a new era: the era of the Inter- 
net-of-Things (IoT) [14, 57]. Rijsdijk and Hultink [66, 68] define the concept of product smartness as a combination of the dimensions autonomy, adaptability, reactivity, multifunctionality, ability to cooperate, humanlike interaction, and personality, as well as the extent to which a product possesses one or more of these dimensions. Yet, most of the products exhibiting one or more of these characteristics remain a glamorous vision of future digitized worlds while, in some areas, they are already hitting our lives. Prime examples are Amazon's Echo or smart watches such as the Apple Watch. Soon, even more sophisticated smart products like autonomous cars will gradually become part of our lives. Digitization is accelerating, and companies across all industries are starting to lift their products to a "smart" level [51].

However, despite its increasing relevance, the market has seen a substantially slower than expected pace of smart product adoption [1]. Currently, the reasons for the slow pace of adoption seem to lie mainly in unknown consumer side factors [1]. A major goal of information systems (IS) research is to predict and to enlighten IS acceptance and usage [88]. For smart product adoption, predicting factors might go beyond the traditional acceptance or resistance evaluations based on perceived usefulness and the perceived ease of use suggested as by the Technology Acceptance Model (TAM) [e.g., 13, 71, 82]. Smart products differentiate in a myriad of ways from traditional computers, thus, due to the radical newness of the products and the application contexts, there might also be new and distinct factors driving consumers' adoption decisions. Therefore, practitioners need to gain in-depth insights into the drivers of resistances that need to be overcome. Hitherto, the field of smart products is lacking such insights. Apart from a considerable amount of technology-focused research in IS literature, only very little research has tackled consumer behavioral issues of smart products [for an exception see: 45 or 73]. Also, there is an apparent lack of initial exploratory research in the field which is reminiscent of the time when ecommerce was a rising phenomenon. Nonetheless, at the time, research on ecommerce benefitted greatly from the combination of inductive, exploratory approaches followed by deductive, confirmatory research [44, 63].

Against this backdrop, exploratory research is needed. Thus, we take a cognition perspective and use projective mapping and free associations as powerful tools in order to explore mental models with regard to smart products. The goal of this research is thus to identify consumers' mental model with regard to different smart product concepts. Increasing the understanding of the existing mental model is expected to be essential in order to obtain further insights into potential sources of adoption barriers and resistances on the consumers' side [43, 64]. Moreover, past research has shown that if for example consumers' existing knowledge structures are applied to promotional messages, consumer understanding is facilitated [23]. Consequently, such increased understanding decreases the perceived complexity and may leverage adoption. From an academic perspective, the emerging insights may as well pave the way for more product-centred research endeavors in a next step. Two overall research questions were developed that should guide the reader through this work: (1) What is the mental model consumers hold towards different smart product concepts?, and (2) What are the dominant mental dimensions based on which consumers differentiate smart product concepts?

On a broader level, this research aims to add value to IS research through method diversity. This paper showcases how non-IS scholars apply new methodologies to an 
IS phenomenon in order to introduce new perspectives, disrupt traditional epistemic scripts, and thereby to enrich the field's knowledge ecology as a whole [5, 24, 70]. Moreover, this research is embedded in an overarching mixed-method agenda [37, 83, 84]. It thus follows the repeated calls for methodological pluralism and mixed-method application in IS knowledge generation [83, 84].

The remainder of the paper is organised as follows: Section 2 provides a summary of the underlying theory. Section 3 presents the applied research method and the study design. Following, section 4 gives an overview of some of the preliminary results. The Discussion, Contributions and Research Implications are described in section 5. Finally, the paper concludes with section 6.

\section{Theoretical Background}

\subsection{Innovation Resistance}

Innovation adoption and acceptance have been the focus of academic literature for some time [e.g., 3, 18, 47, 48, 71, 82]. Most of this research postulates that consumers are open to adopting innovations. However, such pro-innovation bias in current research tends to overshadow the reality of (high-tech) innovation failures with average failure rates of 40-50\% [9, 15, 17, 64]. Innovation adoption arises solely if consumer side resistances can be overcome [64]. Therefore, it is essential to investigate these resistances and their nature [19, 64]. Generally, Ram [64] describes them as being dependent on the three factors perceived innovation characteristics, consumer characteristics, and characteristics of propagation mechanisms. In this description, the consumer characteristics are defined as a combination of psychological variables and demographics. Moreover, Ram [64] describes the psychological variables as a combination of one's personality, attitudes, value orientation, previous innovative experiences, perceptions and beliefs. In order to understand the psychology of innovation resistance, in this study, the psychological variables of consumers will be specifically targeted $[64,75]$. The combined psychological variables such as beliefs or perceptions are held in mental models or cognitive schemas. Bagozzi and Lee [4]. for example introduce mental models as the cognitive representation of the set of ideas a consumer holds about an innovation and that may guide the consumer through the adoption process. Such mental models about product innovation have an important selfregulatory function in the product adoption process [4]. Generally, mental models are an artefact of the overall naïve understandings that humans hold for the world surrounding them and may thus provide clues about sources of resistances.

\subsection{The Role of Mental Models and Their Structure}

There is broad consensus on the existence of mental models and their appearance as small-scale models of external reality that guide human reasoning and decisionmaking [9, 11, 38, 39, 40, 41, 43, 58, 60, 89]. The history of mental models dates back to René Descartes who defines ideas as representations of reality. In this regard, 
he distinguishes between three kinds of ideas: ideae innatae, ideae adventitiae, and ideae factitiae. Thereby ideae factitiae (the fabricated idea) gets most closely to what Ludwig Wittgenstein [89] in his Tractatus Logico-Philosophicus describes by humans developing pictures of facts and define them as models of reality. This idea is in line with Johnson-Laird [40] who supports these notions by defining mental models as the ultimate output of perceptual processes. Later, mental models are further described as small-scale models of reality that are formed through interaction with a target system (e.g., any kind of information regarding the target system 'smart product') which needs to be neither wholly accurate and thorough nor correspond completely with what they model in order to be useful $[38,58]$. In this regard, mental models can be cognitively represented in the form of visual images or they can be abstract and nonvisual [41]. Moreover, there is no need for humans to understand their surrounding reality up to their fundamental principles in order to form mental models [38]. Furthermore, human mental models should by no means be expected to be neat and elegant but rather messy, sloppy, and incomplete representations of people's perceived environment and sometimes derived from idiosyncratic interpretations [57, 58].

The connection between mental models and (consumer) behavior has been acknowledged for some time in the fields of organization science, system science, marketing, and computer science [e.g., 27, 50, 55, 60, 87, 90, 91]. In consumer research, cognitive structures are investigated mostly in terms of product perceptions, brand attitudes, brand-attribute beliefs or brand personality. As soon as consumers gain new information and connect it with existing knowledge, they are assumed to form cognitive structures in their memory in the form of mental models. Furthermore, in marketing and innovation literature, mental models are described as the interpreted meanings of a product or thing (i.e., a target system) that are formed through experience with a target system (e.g., interacting with the product, reading, online information etc.) and guide consumers' behavior [4, 10, 12, 30, 58, 60, 74, 76, 77, 90, 91]. Zaltman and Coulter $[90,91]$ postulate that these mental models essentially drive consumers' thoughts and behaviors. However, a major challenge for research is to elicit such mental models and to bring them to life.

Theories of mental model formation are frequently built on similarity judgments (similarity of objects) [25]. In this context, consumers cognitively represent similarities of different product alternatives through the use of comparison attributes [35]. These attributes have either the characteristic of distinct product features or more abstract dimensions [e.g., 79, 80]. In product category choice situations or in choice situations among rather non-comparable product alternatives, consumers use such abstract comparison dimensions (e.g. practicality) [34]. Thereby, the level of abstraction of these dimensions differs based on the consumers' level of experience or expertise with regard to the focal domain. Novices are expected to compare different products on broader and more general, abstract dimensions [85]. In general, the dimensions describe a range of unique attributes or concepts in consumers' knowledge with respect to a specific domain [42]. The product category smart product contains a wide range of different products such as autonomous cars or home assistants. These products are rather non-comparable on an attribute or functional level as they, by their inherent nature, satisfy different needs. However, consumers might compare them on the basis of general and abstract dimensions such as 'necessity' or 'frightening' and thus create a generic mental model for the category of smart products [32]. These 
overall abstract dimensions that are used by consumers to categorize different smart product concepts are expected to provide important indicators about the basic sources of resistances. Johnson et al. [35] find that when studying consumers on a product category level, spatial scaling methods are most appropriate for determining consumers' latent mental dimensions that might drive consumer behavior. Inductively labelling these mental dimensions can be done by analyzing consumers' underlying semantic structures collected by methods such as open-ended interviewing, free associations or pattern notes [9]. These identified dimensions are expected to represent the first and most important parameters whose adjustment may leverage smart product adoption.

Based on a synthesis of the outlined theory, this work's research approach is epitomized by the following exploratory research propositions: (P1) Smart product resistances are organized in a mental model that crucially guides consumers' adoption process. (P2) Unveiling the content of the mental model may shed light on the general nature of factors that induce smart product resistances. (P3) Spatial scaling and semantic structures are appropriate for eliciting the key dimensions consumers use to mentally categorize different smart product concepts.

\section{$3 \quad$ Research Method and Study Design}

In academia, there has been a considerable debate on how to model and map cognitive representations and mental models [20,43], in particular in the field of IS [53]. In general, multidimensional analysis methods (e.g., Multidimensional Scaling - MDS, Multiple Factor Analysis - MFA or Generalized Procrustes Analysis - GPA) are among the most widely used techniques for exploring and modeling cognitive representations or psychological spaces with regard to product categories $[26,33,35,60$, $78,86]$. Furthermore, the application of such methods is expedient in exploratory settings in which the underlying concepts and dimensions are not developed yet [72]. Projective mapping, particularly well-suited for the inductive set-up of this work's research, will be applied. The quantitative-descriptive method collects data by means of free-choice profiling. Hitherto, it was applied mainly in the field of psychophysics $[62,69]$. Originally, it stems from free sorting tasks pursued in experimental psychology to uncover - via statistical analyses - the structure of stimuli in a perceptual space as well as to interpret the underlying categorization dimensions of these spaces [see e.g. 31 or 52]. In projective mapping, participants directly position products or proxies (e.g. tokens) on a sheet of paper based on perceived similarity and dissimilarity judgments as well as provide descriptive free association data for each product [66]. Afterwards, the data can be analyzed using GPA and MFA. This allows for generating a spatial, lower dimensional consensus configuration from a set of individual configurations.

Compared to other scaling methods, this method has a number of advantages. This technique compares all stimuli at once and not by means of pairwise comparisons. This helps to prevent participant fatigue. Also, the projective mapping method is faster because each positioning of a stimulus reflects multiple similarity/dissimilarity judgements. In an initial exploratory setting, it therefore reveals the most important 
cognitive dimensions faster and easier than other scaling techniques or qualitatively driven mental model elicitation practices such as for example the Zaltman metaphor elicitation technique (ZMET) [56, 90]. Moreover, considering the set of stimuli holistically means that the relationships between multiple pairs are considered in context, as all stimuli are always in view. This appears to be more realistic when it comes to real consumer evaluations of product categories and is thus a major advantage of this technique [46]. It is important to determine the mental model of consumers without deductively encouraging the use of specific evaluative dimensions. Thus, projective mapping suits very well the inductive purpose of this study as it can easily be combined with qualitative data collection methods. Thus, to inductively derive the dimensions, the approach was combined with free associations an established tool in order to efficiently elicit mental models [9]. Participants had to state one free association per product concept. These associations can be plotted into the consensus map in the form of a semantic cloud allowing for inductive interpretation of the axes. Hence, combining projective mapping with the informative quality of free associations allows one to develop the mental dimensions directly from the data.

The participants for the study were recruited on the campus of a large public university $\left(N=40, M_{\text {age }}=31.6\right.$ years, $50 \%=$ women $)$. All participants were offered free refreshments as an incentive. All participants took part voluntarily. The participants were randomly assigned to one of the two study groups (group 1: $N=20$ and group 2: $N=20$ ). The study was conducted in German, the native language of all participants. The stimuli consisted of 16 consumer-oriented smart product concepts, eight of which are not commercially available yet (e.g. autonomous vehicle), while the other eight have already been released on the market (e.g. smart watch). The two groups were derived in order to reveal differences between mental models of released and unreleased products, i.e. differences between established and unestablished products. The participants had to be familiar with all of the released product concepts. The smart product concepts were chosen on the basis of the suggested smartness criteria proposed by Rijsdijk and Hultink [65, 67] and on their ability to possess at least one of them. The study was conducted in a controlled laboratory setting. Participants received a brief introduction regarding the different smart product concepts from the researcher. They were then given 10-15 minutes to read the concept descriptions again in detail and familiarize themselves with them. For each concept, a token was provided representing a proxy for the mapping task. In a next step, the participants were asked to position the tokens on a large sheet of blank paper; in practice, this sheet is a paper tablecloth measuring $40 \mathrm{~cm} \times 60 \mathrm{~cm}$. Figure 1 shows an example of an individual configuration. The following instructions were given to the participants:

1) "You are asked to evaluate the similarities (or dissimilarities) between several smart product concepts. You can do this intuitively, based on your own criteria (except product function), those that you consider substantial. You do not have to specify your criteria. There is no right or wrong."

2) "You have to position the tokens on the tablecloth in such a way that two smart product concepts are positioned close to one another if they appear identical to you and that two smart product concepts are positioned further away from one another if they appear dissimilar to you. Do not hesitate to 
make use of the entire sheet to strongly express the differences you perceive."

In a next step, the participants had to indicate one free association per product concept. In addition, they had to specify whether their association was positively $(+)$, neutrally (/) or negatively (-) connoted. Coordinates were read off and entered into the data matrix.

The derived data matrix consists of $\mathrm{N}$ participants in the columns and $\mathrm{K}$ product concepts and free associations in the rows, each of them represented by a group consisting of one $\mathrm{x}$ and one $\mathrm{y}$ coordinate, respectively. The data was analyzed using MFA and GPA [26]. The analysis was pursued in R using the Rcmdr Plugin for the FactoMineR package. The analysis generated lower dimensional, spatial consensus configurations from the individual participant's configurations. In the derived consensus maps, the rows of the original data matrix are represented as points. The points represent the group average position of the individual's positioning of the product concept. The closer the points are positioned to one another on the map, i.e. the shorter the distance between the points, the more similar they are perceived in the eye of the consumer. Lastly, the derived consensus configurations allow to inductively deducing the central dimensions that were used by the consumers to categorize the different product concepts. The free association data can be superimposed onto the consensus maps, which allowed for the qualitative dimensional interpretation by two independent assessors.
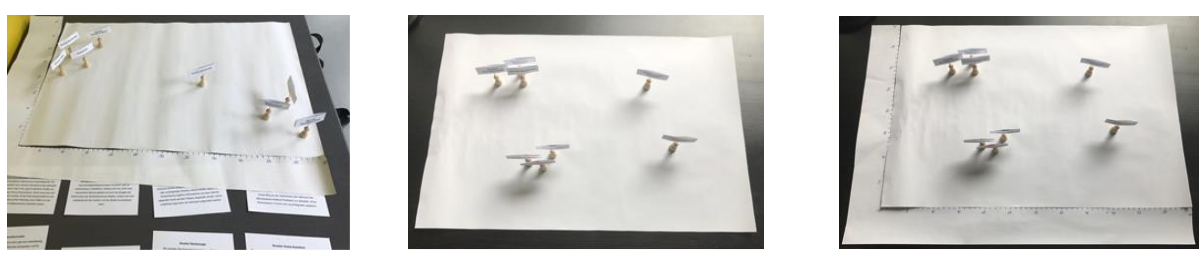

Figure 1. Individual positioning of the smart product concept tokens from one study participant

\section{Preliminary Results}

Although the collected data allows for more in-depth analysis on product and category level, due to limited space, only some of the initial exploratory results of the unreleased group will be outlined very briefly in this paper. Figure 2 represents the consensus configuration from the unreleased group and the semantic cloud that was derived using GPA. The MFA reveals that the two dimensions (Dim 1 and Dim 2) account for more than $53 \%$ of the variance in the underlying data. Apparently, there are two very dominant dimensions based on which the participants categorized the different product concepts. Here, dimension 1 describes most of the variance of the participants' categorizations $(30,74 \%)$. Besides, the vertical dimension 2 clearly separates the smart product concept ' 8 _AV' from all the other smart product concepts. 

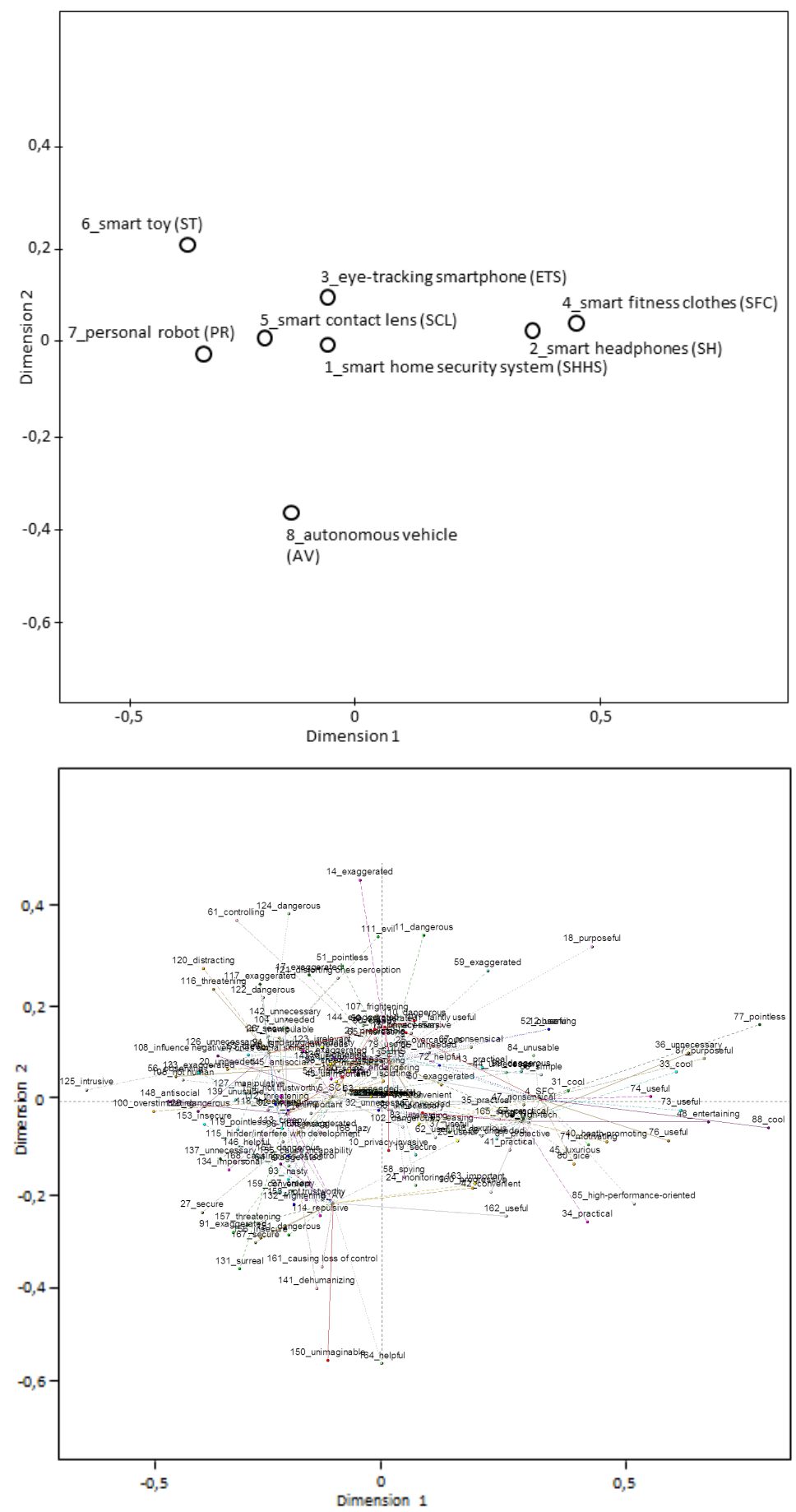

Fig. 2. Consensus configuration (above) and superimposed semantic cloud (below) 
Moreover, '2_SH' and '4_SFC' are mentally categorized as being very similar. Interpreting the free association data will help shed light on the qualitative meaning of the mental dimensions. From a dimensional perspective, most of the free associations from the semantic cloud are organized along the horizontal dimension. On the left, they are highly emotional and negatively associated. Products are mostly linked to associations such as 'intrusive', 'spying on', 'observing' or 'controlling'. On the right, free associations comprise mainly rational, more positive words such as 'useful', 'practical'. In fact, consumers appear to categorize the product concepts mainly along an 'intrusive-useful' dimension. This categorization could reflect some form of consumers' cost-benefit balancing. Regarding the product concepts, it appears that for '2_SH' and '4_SFC', the perceived benefits of usefulness outweigh the perceived costs of intrusion. In contrast, for '6_ST', '7_PR' or '5_SCL' the perceived costs of intrusion seem to prevail. This could imply that for product concepts that involve contact with children, the perceived negative potential of these products is predominant, whereas for more playful and leisure-like applications, the perceived usefulness seems to predominate. Interpretation of the vertical dimension is less clear. However, one could interpret it as an overall dimension of danger. Here, the dimension seems to vary in concreteness. With regard to ' $8 \mathrm{AV}^{\mathrm{A}}$ ', the associated fear is concrete and mainly due to a perceived loss of control (e.g. free association 'loss of control'). On the other hand, '6_ST' and '3_ETS' are associated with fear on a more general level, which is reflected by terms such as 'dangerous' and 'threatening'. In sum, the two dimensions (accounting for $>53 \%$ of the variance) appear to consist of an 'intrusiveuseful' dimension (Dim 1) and a generic 'fear' dimension (Dim 2). These dimensions seem to be the predominant dimensions based on which consumers mentally categorize and distinguish different unreleased smart product concepts. From a product perspective, the smart product concepts '5_SCL', '7_PR' and '6_ST' in particular appear to have a strong negative connotation in consumers' mental representations. The smart toy was rated negatively by all of the participants, the personal robot by $90 \%$ and the smart contact lens by $85 \%$. In general, higher degrees of complexity and radicalism of the smart product concept appear to be aligned with an increase in negative judgments. It could be inferred that increased levels of complexity and radicalism confuse or frighten consumers. In contrast, '4_SFC' and '2_SH' invoke positive connotations and are perceived as useful and cool. Even though only the results from the unreleased smart product group could be outlined briefly here, Table 1 shows the preliminary results of both groups.

Table 1. Mental model summary

\begin{tabular}{|c|c|c|}
\hline $\begin{array}{l}\text { Mental } \\
\text { sions }\end{array}$ & Study group 1: unreleased & Study group 2: released \\
\hline Dimension 1 & 'intrusive - useful' & Usefulness: 'useful - useless' \\
\hline Dimension 2 & $\begin{array}{c}\text { Fear: 'abstract (dangerous) - concrete } \\
\text { (loss of control)' }\end{array}$ & $\begin{array}{l}\text { Efficiency: 'efficient' - 'ineffi- } \\
\text { cient' }\end{array}$ \\
\hline $\begin{array}{l}\text { Overall mental } \\
\text { model }\end{array}$ & $\begin{array}{l}\text { Predominantly negative conno- } \\
\text { tations, emotionally laden }\end{array}$ & $\begin{array}{l}\text { Predominantly positive connota- } \\
\text { tions and highly rational }\end{array}$ \\
\hline
\end{tabular}




\section{Discussion, Contributions and Research Implications}

To date, research providing inductively derived evidence with regard to resistance to smart product concepts is lacking. This research thus contributes to closing this revealed gap by providing initial insights into the psychological drivers that may cause adoption resistances [4, 64]. In light of our preliminary findings, this section will discuss the main contributions of this research paper as well as outline promising avenues for future research.

The preliminary findings seem to provide a clue about a simplifying heuristic or so-called "click" experience that consumers may apply in their evaluation of unreleased smart products $[21,54]$. In general, heuristics help to release the complexity from a decision task and thus to reduce cognitive effort and to increase decision making efficiency [81]. Based on our findings, in their initial evaluations of unreleased smart product concepts, consumers seem to put great emphasis on the degree of their intrusive potential. This factor is highly negatively connotated and may therefore represent a significant hindering factor to the adoption of future smart product concepts. Consequently, and due to the technological complexity of smart products, consumers may strive to reduce situational complexity by using the level of perceived intrusion as a heuristic that becomes decisive for adoption or resistance. In this context, our future research will dig deeper and move in the following four directions: (1) consumers evaluations of released versus unreleased smart product concepts; (2) the exact evaluation and decision making styles prior to the adoption of yet unreleased smart products; (3) investigation of the specific product factors that have the most impact on the calculus between the perceived benefit of usefulness and the perceived cost of intrusion [16]. Especially for practice it is of great relevance to increase knowledge about such factors and their psychological impacts as they could represent possible starting points that might be addressed to leverage adoption; (4) the gradual increase of functions in use. Such updates ex-post market release could help to gradually accustom the user to radically new product functions instead of overwhelming the user from the beginning, and thus may avoid resistances.

In addition, having read this work one should bear in mind that it is embedded in an overarching mixed-method agenda whose findings are used to inform a set of confirmatory research endeavors [37, 83, 84]. Following the epistemological idea of the dialectic pluralism, the use of multiple methods and perspectives is expected to add substantial value to research on IS phenomena [36]. The complexity of the focal phenomenon and its interplay with the social environment calls for such a multiple perspective approach in order to be inclusive and to increase the general robustness of the findings [8, 83]. This study contributes with initial, inductively generated knowledge that helps to pave the way for future deductive studies. Going forward, the designs of these studies will be built on the elicited mental models and will deductively develop, complement and validate our initial findings [22]. Further related activities include: (1) a construct development (perceived intrusion of smart products). In relation to Bhattacherjee and Hikmet [22] it seems likely that the revealed aspect of perceived intrusion is unique and specific to the domain of smart technologies and thus needs to be treated as a distinct construct. Thus, we follow the call of Bhattacherjee and Hikmet [22] to dig deeper into understanding the multifaceted phenomenon of resistance by investing in the development of constructs that may 
represent significant drivers of resistance to a specific technology; and (2) the development of a research model of smart product adoption that can be tested deductively. In this way, we hope to provide empirical evidence on the exact nomological paths that shape individuals' resistance to smart products [29].

Lastly, we contribute to the current body of knowledge on IS failures [17] as well as to the field of IS in general through method diversity. This paper showcases how non-IS scholars apply new methods to an IS phenomenon towards introducing new perspectives, disrupt traditional epistemic scripts, and thereby enrich the field's knowledge ecology as a whole [5, 70]. In Grover's [24] terms, we think that this research follows the call of pushing IS research to the edges by introducing a new methodological approach. More precisely, it contributes to the 'left edge' through a new form of inductive knowledge production resulting in an innovative dataset.

\section{Conclusion}

The aim of this paper was to uncover the hitherto unstudied mental models regarding smart product concepts. Building on mental model and innovation resistance theory, a set of exploratory research propositions was developed. Preliminary results of one empirical study revealed that consumers categorize released smart product concepts mainly based on a rationally laden useful-useless dimension and unreleased products along with a very emotionally laden intrusive-useful dimension. Building on our study, we extract knowledge gaps that warrant future investigation, as well as outline implications for practitioners.

The presented findings should be interpreted in light of its limitations. First, our study might be limited due to the overall exploratory research layout. We used a relatively small number of participants, which might not be representative of the whole population. Thus, we would welcome additional rigorous and possibly quantitative studies to specifically confirming our exploratory findings. Given that our data collection was performed in Germany, we are aware that the generalizability of our findings might be also limited due to the cultural setting that may differ from others in terms of cultural beliefs [28]. In conclusion, we hope that IS research benefits from the above findings as well as we hope to fuel future research on the adoption and resistance of smart technologies.

\section{References}

1. Accenture (2016). Igniting Growth in Consumer Technology. Customer survey.

2. Accenture (2015). The Internet of Things: The Future of Consumer Adoption. Market report.

3. Agarwal, R. and J. Prasad (1999). "Are individual differences germane to the acceptance of new information technologies?.” Decision sciences, 30 (2), 361-391.

4. Bagozzi, R.P. and K.H. Lee (1999). "Consumer Resistance To, and Acceptance Of, Innovations.” In:NA - Advances in Consumer Research. Ed. by E. J. Arnould and L. M Scott. Provo, UT: Association for Consumer Research, pp. 218-225. 
5. Benbasat, I. and R.W. Zmud. (2003). "The Identity Crisis within the IS Discipline: Defining and Communicating the Discipline's Core Properties." MIS Quarterly, 27 (2), 183-194.

6. Bhattacherjee, A. and N. Hikmet (2007). "Physicians' resistance toward healthcare information technology: A theoretical model and empirical test," European Journal of Information Systems, 16 (6), 725-737.

7. Castellion, G. and S. K. Markham (2013). "Perspective: new product failure rates: influence of argumentum ad populum and self-interest." Journal of Product Innovation Management, 30 (5), 976-979.

8. Cao, J., J.M. Crews, M. Lin, A. Deokar, J.K. Burgoon and J.F. Nunamaker Jr (2006). "Interactions between system evaluation and theory testing: a demonstration of the power of a mulitfaceted approach to systems research." Journal of Management Information Systems 22 (4), 207-235.

9. Carley, K., and M. Palmquist (1992). "Extracting, Representing, and Analyzing Mental Models." Social Forces, 70(3), 601-636.

10. Christensen, G. L. and J.C. Olson (2002). "Mapping Consumers' Mental Models with ZMET." Psychology and Marketing 19 (6), 477-501.

11. Craik, K. J. W. (1943). “The Nature of Explanation.” Cambridge: Cambridge University Press.

12. Cuny, C., and T. Opaswongkarn (2017). "Why Do Young Thai Women Desire White Skin? Understanding Conscious and Nonconscious Motivations of Young Women in Bangkok." Psychology and Marketing, 34 (5), 556-568.

13. Davis, F.D., R.P. Bagozzi and P.R. Warshaw (1989). "User Acceptance of Computer Technology: A Comparison of Two Theoretical Models." Management Science, 35 (8), 982-1003.

14. Deloitte (2015). Smart Cities report: How rapid advances in technology are reshaping our economy and society. Market report.

15. Deschamps, J.P. (2017). "Classic Root Causes of Innovation Failures - Things We All Know but Sometimes Forget." In: Strategy and Communication for Innovation. Ed. By N. Pfeffermann and J. Gould. Springer International Publishing, pp. 41-60.

16. Dinev, T. and P.Hart (2006). "An extended privacy calculus model for e-commerce transactions." Information systems research, 17 (1), 61-80.

17. Dwivedi, Y. K., D. Wastell, S. Laumer, H. Z. Henriksen, M. D. Myers, D. Bunker, A. Elbanna, M. N. Ravishankar and S. C. Srivastava (2015). "Research on information systems failures and successes: Status update and future directions." Information Systems Frontiers, 17 (1), 143-157.

18. Dwivedi, Y. K., N. P. Rana, A. Jeyaraj, M. Clement and M. D. Williams (2017). "Reexamining the unified theory of acceptance and use of technology (UTAUT): Towards a revised theoretical model." Information Systems Frontiers, 1-16.

19. Ellen, P.S., W.O. Bearden and S. Sharma (1991). "Resistance to Technological Innovations. An Examination of the Role of Self-Efficacy and Performance Satisfaction." Journal of the Academy of Marketing Science, 19 (4), 297-307.

20. Gärdenfors, P. (2000). Conceptual Spaces. Cambridge, MA: MIT Press/Bradford Books.

21. Gigerenzer, G. and D. G. Goldstein (1996). "Reasoning the fast and frugal way: Models of bounded rationality." Psychological Review, 103 (4), 650-669.

22. Greene, J., V. Caracelli and W. Graham (1989). "Toward a Conceptual Framework for Mixed-Method Evaluation Design.” Educational Evaluation and Policy Analysis 11 (3), 255-274.

23. Gregan-Paxton, J. and D.R. John (1997). "Consumer learning by analogy: A model of internal knowledge transfer." Journal of Consumer Research, 24 (3), 266-284.

24. Grover, V. and K. Lyytinen (2015). "New State of Play in Information Systems Research: The Push to the Edges.” Mis Quarterly, 39 (2), 271-296. 
25. Goldstone, R. (1994). "An Efficient Method for Obtaining Similarity Data." Behavior Research Methods, Instruments, and Computers, 26 (4), 381-386.

26. Gower, J. C. (1975). "Generalized procrustes analysis." Psychometrika, 40 (1), 33-51.

27. Hill, R.C. and M. Levenhagen (1995). "Metaphors and Mental Models: Sensemaking and Sensegiving in Innovative and Entrepreneurial Activities." Journal of Management, 21 (6), 1057-1074.

28. Hofstede, G. (2011). Culture's consequences: Comparing values, behaviors, institutions, and organizations across nations, Thousand Oaks, Calif.: Sage Publ.

29. Hughes, D. L., Y. K Dwivedi, N. P. Rana and A. C. Simintiras (2016). Information systems project failure-analysis of causal links using interpretive structural model-ling. Production Planning \& Control, 27(16), 1313-1333.

30. Ilyuk, V., L. Block and D. Faro (2014). "Is It Still Working? Task Difficulty Promotes a Rapid Wear-Off Bias in Judgments of Pharmacological Products.” Journal of Consumer Research, 41 (3), 775-793.

31. Imai, S. (1966). "Classification of Sets of Stimuli with Different Stimulus Characteristics and Numerical Properties." Perception and Psychophysics, 1, 48-54.

32. Johnson, M.D. (1984). "Consumer choice strategies for comparing noncomparable alternatives.” Journal of Consumer Research, 11 (3), 741-753.

33. Johnson, M. D. and E. J. Hudson (1998). "On the perceived usefulness of scaling techniques in market analysis." Psychology \& Marketing, 13 (7), 653-675.

34. Johnson, M.D. and J. Kisielius (1985). "Concreteness-Abstract-Ness and the FeatureDimension Distinction." Advances in Consumer Research, 12, 325-328.

35. Johnson, M.D., D.R. Lehmann, C. Fornell and D.R. Horne (1992). "Attribute abstraction, feature-dimensionality, and the scaling of product similarities." International Journal of Research in Marketing, 9 (2), 131-147.

36. Johnson, R.B. (2017). "Dialectical Pluralism: A Metaparadigm whose Time has come." Journal of Mixed Methods Research, 11 (2), 156-173

37. Johnson, R.B. and A.J. Onwuegbuzie (2004). "Mixed methods research: A research paradigm whose time has come." Educational researcher, 33 (7), 14-26.

38. Johnson-Laird, P.N. (1980). "Mental Models in Cognitive Science." Cognitive Science, 4 (1), 71-115.

39. Johnson-Laird, P.N. (1983). "Mental Models and Thought." In: The Cambridge Handbook of Thinking and Reasoning. Ed. by K.J. Holyoak and R.G. Morrison, pp. 185-208.

40. Johnson-Laird, P.N. (2001). "Mental Models and Deduction." Trends in Cognitive Sciences, 5 (10), 434-442.

41. Johnson-Laird, P.N. and R.M. Byrne (2002). "Conditionals: A Theory of Meaning, Pragmatics, and Inference.” Psychological Review, 109 (4), 646-678.

42. Kanwar, R., J.C. Olson and L.S. Sims (1981). "Toward Conceptualizing and Measuring Cognitive Structures.” In: Advances in Consumer Research, Ed. by K.B. Monroe and A. Arbor. MI: Association for Consumer Research, pp. 122-127.

43. Kearney, A.R. and S. Kaplan (1997). "Toward a Methodology for the Measurement of Knowledge Structures of Ordinary People: the Conceptual Content Cognitive Map (3CM).” Environment and Behavior, 29, 579-617.

44. Keeney, R.L. (1999). "The Value of Internet Commerce to the Customer." Management Science, 45 (4), 533-542

45. Kim, K.J. and D.-H. Shin (2015). "An acceptance model for smart watches: Implications for the adoption of future wearable technology." Internet Research, 25 (4), 527-541.

46. Kriegeskorte, N. and M. Mur (2012). "Inverse MDS: Inferring Dissimilarity Structure from Multiple Item Arrangements." Frontiers in Psychology, 3, 245.

47. Lapointe, L. and S. Rivard (2005). "A multilevel model of resistance to information technology implementation.” MIS quarterly, 29 (3), 461-491. 
48. Laumer, S. and A. Eckhardt (2012). "Why do people reject technologies: a review of user resistance theories." Information systems theory, pp. 63-86. Springer New York.

49. Love, E. and E.M. Okada (2015). "Construal based marketing tactics for high quality versus low price market segments." Journal of Product \& Brand Management, 24 (2), 172-181.

50. Mathieu, J.E., T.S. Heffner, G.F. Goodwin, E. Salas and J. A. Cannon-Bowers (2000). "The Influence of Shared Mental Models on Team Process and Performance." Journal of Applied Psychology, 85 (2), 273-283.

51. McKinsey Global Institute (2015). The Internet of Things: Mapping the Value beyond the Hype. Market report.

52. Miller, G.A. (1969). "A psychological method to investigate verbal concepts." Journal of Mathematical Psychology, 6, 169-191.

53. Montazemi, A.R. and D.W. Conrath (1986). The Use of Cognitive Mapping for Information Requirements Analysis. MIS Quarterly, 10 (1), 45-56.

54. Montgomery, H. (1983). "Decision rules and the search for a dominance structure: Towards a process model of decision making." Advances in psychology 14, 343-369.

55. Moran, T.P. (1981). "Guest Editor's Introduction: An Applied Psychology of the User." ACM Computing Surveys (CSUR), 13 (1), 1-11.

56. Nestrud, M. A. and H.T. Lawless (2010). "Perceptual mapping of apples and cheeses using projective mapping and sorting." Journal of Sensory Studies, 25 (3), 390-405.

57. Ng, I.CL. and S. YL. Wakenshaw (2017). "The Internet-of-Things: Review and research directions." International Journal of Research in Marketing 34 (1), 3-21.

58. Norman, D.A. (1983a). "Some Observations on Mental Models." In: Mental models. Ed. by D. Gentner and A. L. Stevens. Lawrence Erlbaum Associates. NJ: Hillsdale, pp. 7-14.

59. Norman, D.A. (1983b). "Design Rules Based on Analyses of Human Error." Communications of the ACM, 26 (4), 254-258.

60. Norman, D. (2013). The Design of Everyday Things: Revised and Expanded Edition. New York: Basic Books (AZ).

61. Nosofsky, R.M. (1992). "Similarity Scaling and Cognitive Process Models." Annu. Rev. Psychology 43, 25-53.

62. Pagès, J. (2005). "Collection and analysis of perceived product inter-distances using multiple factor analysis: Application to the study of 10 white wines from the Loire Valley." Food quality and preference, 16 (7), 642-649.

63. Pavlou, P. A. and M. Fygenson (2006). "Understanding and predicting electronic commerce adoption: An extension of the theory of planned behavior." MIS Quarterly, 115143.

64. Ram, S. (1987). “A Model of Innovation Resistance.” In: ACR NA - Advances in Consumer Research, 14. Ed. by M. Wallendorf and P. Anderson. Association for Consumer Research. UT: Provo, pp. 208-212.

65. Rijsdijk, S.A. and E.J. Hultink (2002). "The Impact of Product Smartness on Consumer Satisfaction through Product Advantage, Compatibility, and Complexity.” In: Proceedings of the 13th PDMA Research Conference, Orlando.

66. Rijsdijk, S.A. and E.J. Hultink (2003). "Honey, Have You Seen Our Hamster? Consumer Evaluations of Autonomous Domestic Products." Journal of Product Innovation Management, 20 (3), 204-216.

67. Rijsdijk, S.A. and E.J. Hultink (2009). "How Today's Consumers Perceive Tomorrow's Smart Products." Journal of Product Innovation Management, 26 (1), 24-42.

68. Rijsdijk, S.A., E.J. Hultink and A. Diamantopoulos (2007). "Product Intelligence: its Conceptualization, Measurement and Impact on Consumer Satisfaction. Academy of Marketing Science, 35 (3), 340-356. 
69. Risvik, E., J.A. McEwan, J.S. Colwill, R. Rogers and D.H. Lyon (1994). "Projective Mapping: A Tool for Sensory Analysis and Consumer Research." Food Quality and Preference, 5 (4), 263-269.

70. Robey, D. (1996). "Diversity in Information Systems Research: Threat, Promise, and Responsibility." Information Systems Research, 7 (4), 400-408.

71. Rogers, E.M. (1976). "New Product Adoption and Diffusion.” Journal of Consumer Research, 2 (4), 290-301.

72. Schiffman, S.S., M.L Reynolds and F.W. Young (1981). "Introduction to Multidimensional Scaling: Theory, Methods, Applications.” Academic Press, New York.

73. Schweitzer, F. and E. van den Hende (2016). "To Be or Not to Be in Thrall to the March of Smart Products." Psychology and Marketing, 33 (10), 830-842.

74. Schweitzer, F. and E. van den Hende (2017). "Drivers and Consequences of Narrative Transportation: Understanding the Role of Stories and Domain-Specific Skills in Improving Radically New Products.” Journal of Product Innovation Management, 34 (1), 101-118.

75. Sheth, J.N. (1981). "Psychology of Innovation Resistance: The Less Developed Concept (LDC) in Diffusion Research." Research in Marketing, 4, 273-282.

76. Strandvik, T., M. Holmlund and B. Edvardsson (2012). "Customer needing: a challenge for the seller offering." Journal of Business \& Industrial Marketing, 27 (2), 132-141.

77. Sugai, P. (2005). "Mapping the Mind of the Mobile Consumer Across Borders: An Application of the Zaltman Metaphor Elicitation Technique." International Marketing Review, 22 (6), 641-657.

78. Torgerson, W.S. (1952). "Multidimensional Scaling: I. Theory and Method." Psychometrika, 17, 401-419.

79. Tversky, A. (1977). "Features of similarity." Psychological review, 84 (4), 327.

80. Tversky, A. and I. Gati (1978). "Studies of similarity." Cognition and Categorization 1, 79-98.

81. Tversky, A. and D. Kahneman (1974). "Judgment under Uncertainty: Heuristics and Biases." Science, 185, 1124-1131.

82. Venkatesh, V. and F.D. Davis (2000). "A Theoretical Extension of the Technology Acceptance Model: our Longitudinal Field Studies.” Management Science, 46 (2), 186204.

83. Venkatesh, V., S.A. Brown and H. Bala (2013). "Bridging the Qualitative - Quantitative Divide: Guidelines for Conducting Mixed Methods research in Information Systems." MIS Quarterly, 37 (1), 21-54.

84. Venkatesh, V., S.A. Brown and Y.W. Sullivan (2016). "Guidelines for conducting mixed-methods research: An extension and illustration." Journal of the Association for Information Systems, 17 (7), 435.

85. Walker, B., R. Celsi and J. Olson (1987). "Exploring the tructural Characteristics of Consumers' Knowledge.” In: NA - Advances in Consumer Research, 14. Ed. by M. Wallendorf and P. Anderson. Association for Consumer Research. UT: Provo, pp. 17-21.

86. Wedel, M., \& T.H. Bijmolt (2000). "Mixed tree and spacial representations of dissimilarity judgments." Journal of classification, 17 (2), 243-271.

87. Woodside, A.G. (2001). "Editorial: Sense Making in Marketing Organizations and Consumer Psychology: Theory and Practice." Psychology and Marketing, 18 (5), 415-421.

88. Williams, M.D., Y.K. Dwivedi, B. Lal and A. Schwarz (2009), "Contemporary trends and issues in IT adoption and diffusion research." Journal of Information Technology, $24(1), 1-10$.

89. Wittgenstein, L. (1918). Tractatus logico-philosophicus. Wien.

90. Zaltman, G. and R.H. Coulter (1995). "Seeing the Voice of the Customer: MetaphorBased Advertising Research." Journal of Advertising Research, 35 (4), 35-51. 
91. Zaltman, G. (1997). "Rethinking Market Research: Putting People Back." Journal of Marketing Research, 34 (4), 424-437. 